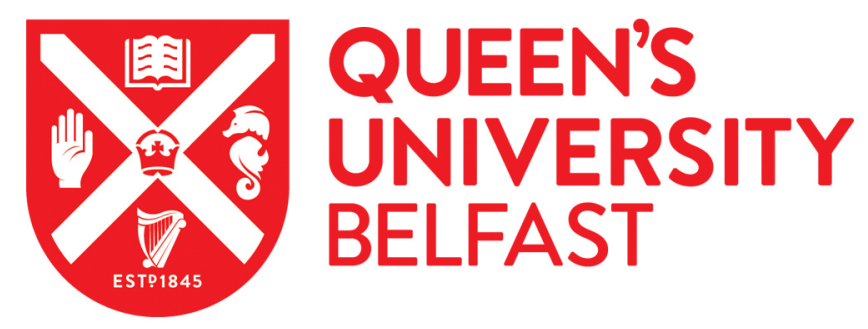

\title{
On Being Let Loose in the Field: The Execution of Professional Ethics
}

McAreavey, R. (2014). On Being Let Loose in the Field: The Execution of Professional Ethics. Sociologia Ruralis, 54(1), 71-93. https://doi.org/10.1111/soru.12010

\author{
Published in: \\ Sociologia Ruralis
}

\section{Document Version:}

Peer reviewed version

Queen's University Belfast - Research Portal:

Link to publication record in Queen's University Belfast Research Portal

\section{Publisher rights}

(C) 2013 The Author. Sociologia Ruralis () 2013 European Society for Rural Sociology

This is the peer reviewed version of the following article: McAreavey, R. (2014), On Being Let Loose in the Field: The Execution of Professional Ethics. Sociologia Ruralis, 54: 71-93., which has been published in final form at

http://onlinelibrary. wiley.com/doi/10.1111/soru.12010/abstract. This article may be used for non-commercial purposes in accordance with

Wiley Terms and Conditions for Self-Archiving.

\section{General rights}

Copyright for the publications made accessible via the Queen's University Belfast Research Portal is retained by the author(s) and / or other copyright owners and it is a condition of accessing these publications that users recognise and abide by the legal requirements associated with these rights.

Take down policy

The Research Portal is Queen's institutional repository that provides access to Queen's research output. Every effort has been made to ensure that content in the Research Portal does not infringe any person's rights, or applicable UK laws. If you discover content in the Research Portal that you believe breaches copyright or violates any law, please contact openaccess@qub.ac.uk. 


\section{On being let loose in the field: The execution of professional ethics}

The theory and practice of rural development, while frequently adjoined within discourse, often represents huge differences between what should be done and what is actually done. Knowledge generated is closely correlated to the problems that are identified and the way in which they are investigated, in the context of the surrounding world (Danermark et al. 2002:26). 'Knowing well' and 'knowing responsibly' (p.125/141) thus requires a continuous, fluid and complex relationship with a 'range of positions and voices that influence conceptualisations of ethical practices' (Cannella and Lincoln 2007:318). This is particularly the case in rural development where a complex network of structures houses a range of increasingly diverse actors. Navigating and negotiating between different interests can be challenging for the rural development practitioner, causing problems if one party perceives that their particular interests have been sidelined in favour of other concerns. For instance, juggling between attaining active engagement while simultaneously providing effective leadership is a tricky 'balancing act' (Convery et al. 2010 p.160). Meanwhile evidence of dominance of elite interests and asymmetrical power relations prevails (Derkzen et al. 2008; McAreavey 2009a, 2009b) and questions of participation and legitimacy continue to arise (Ray 1998, 1999; Shortall and Shucksmith 2001; Bryden 2006). Previous research indicates that a community's capacity to reap the benefit from participation is curtailed in the absence of ongoing support beyond consultation and planning (Schafft and Greenwood 2003; Fujimoto, Isao and Sandoval 2005). The reality of funding programmes, personality differences and other practical matters can impede ideological goals that are rich in aspirations of involvement, participation, empowerment and equality. These matters continue to challenge the practice and effectiveness of rural development activity.

Professional standards and values such as research ethics provides a mechanism by which, as a very minimum, the welfare of rural development actors' may be protected. Professional ethics pays attention to inherent philosophical matters concerned with courses of action and with the morality of consequences. It accentuates the underlying assumption that researchers act with intellectual and ethical integrity (see Zinn 1979) and to paraphrase Tierney and Corwin (2009:396) are not 'morons'. Viewed in this way ethics is a relational process, rather than a one-off endeavour. The decisions and actions of the researcher during the research process will invariably be influenced by a range of factors including philosophical values, pragmatic concerns, experience and the research context (Doucet and Mauthner 2008). Accordingly there is a 'range of positions and voices that influence conceptualisations of ethical practices' (Cannella and Lincoln 2007:318). These other relationships (Doucet and Mauthner 2002, p. 125) include the ones that we have or create with many different communities - readers, users of the research, and the varied knowledge communities that influence our work, including interpretive, epistemological and academic communities. Within rural development this encompasses engagement with recent migrants as well as with longer established social groups.

There is broad consensus within the literature of the conceptualisation of research ethics founded on the principles of non-maleficence, beneficence and autonomy. Despite this general consensus, the very mention of the word 'ethics' triggers a mixture of responses from academic colleagues including eye-rolling, tales of 
battles with Research Ethics Committees (REC) and general feelings of exasperation. This is possibly because ethics are largely associated with ethical scrutiny and the research management process. The current ethical review process can be traced back to medical models from the 1960 s that continue to underpin the ethical regulatory framework in the UK. These original standards were substantially expanded in the wake of scandals due to unauthorised use of human body parts during the 1990s (Boden, Epstein and Latimer, 2009; Truman 2003), with significant impact on other disciplines (Boden et al.2009; ESRC, 2005, 2010). A number of scholars/commentators have gone as far as to suggest that the current ethical review processes employed within universities are less than satisfactory and potentially unethical due to the emerging and ongoing nature of ethics in the research process (see for instance van den Hoonard 2002; Lincoln and Tierney 2004; Hemmings 2006; Hammersley 2009; McAreavey and Muir, 2011). Several issues connected to the ethical review process illustrate some of the fundamental ideological differences between those with an interest in research ethics.

Firstly, the general approach employed to capture research ethics has often resulted in over-generalized responses that attempt to close the gap between what actually happens and what should happen. In particular given the fluidity of the naturalistic settings for social research; the research process cannot be reduced to a template outlining an anticipated course of action. Rather than narrowing the cleft between 'the rational mode and situational demands' (de Laine 2000:136), ethical review can reinforce the gap by paying little attention to the fact that the researchers must respond to events as they unfold in the field. This cannot always take account of moral issues as they arise within the research field (Shaw 2008, Flyvberg 2001). The participatory nature of rural development is illustrative - events cannot be predicted, research and practice are necessarily 'messy' and innovative outcomes often arise as a result of last minute opportunities and circumstances which are not always anticipated.

Secondly, ethical review is used by sponsoring organisations to monitor and attempt to control what happens within the research field. As a tool of management they are about the way in which institutions meet management obligations and monitor the activity of their employees. The bureaucratic, systems approach to ethical review is problematic operating as 'external constraints on, rather than as inner directives for, the research process' (Hammersley and Traianou 2011:382). Ethical issues are thus more and more dismissed as something that is administrative and procedural, yet another layer of bureaucracy with which time pressured and busy academics must engage.

An instrumental process of ethical monitoring appears to have taken precedence over normative debates on ethics (Scott 2004). But ethics concerns both researchers and managers and while they may provide a tool of management, ethics are central to knowledge development: they are constantly revisited through rewriting and reinterpretation (Boden et al. 2009). As researchers we can go along with ethics as they are re-defined by managers and other bureaucrats, or we can attempt to re-claim them for what they really are: an inherent component of the professional practice of research. This is not a benign or wishy-washy concern, Boden et al. (2009) warn that modern ethical bureaucracy is a chimera that masks hidden power and is far removed from 
critical debate on ethical conduct. The fundamental values of academia - collegiality, shared community, autonomy and mutual support - are in danger of being eroded though the effective hijacking of ethics by bureaucrats.

This article responds to intimations from the wider qualitative research literature (see for instance Boden et al. 2009; Hammersely and Traianou 2011; McAreavey and Muir 2011) to reclaim ethics from management imperatives. An argument is made for researchers and practitioners to (re)claim ethics to help address ongoing challenges within the sector and to avoid unnecessary regulation from overzealous managers or colleagues. It is striking how rural development debate is fairly quiet on the question of ethics, leaving guidance to professional bodies. This analysis seeks to relocate ethics from being an annoying requirement of bureaucrats to one where it is inherent to rigorous research and professional practice. It begins by unravelling ethics and ethical regulation before moving on to consider the significance of ethics given a context of increasingly diverse stakeholder groups within rural development, focusing in particular on migrant communities. Empirical evidence reveals how ethics are negotiated, understood and managed as part of a larger research process. Considered in its true meaning ethics becomes an asset to the social science researcher, rather than a liability. In so doing this paper clarifies the distinction between 'bureaucratic ethics' and 'professional-personal ethics'. The analysis illustrates how the latter has the potential to contribute to a strategy of reflexive, situated and participatory practice.

\section{Reflecting on research ethics and research governance}

'Research ethics' has been defined as: 'the moral principles guiding research, from its inception through to completion and publication of results and beyond...' (ESRC 2010:40) and they are typically monitored by review boards such as Research Ethics Committees (REC's) and regulated by ethical codes of professional bodies (such as BSA 2004). For academic researchers the latter advocate principles but carry little power in comparison to university-based RECs (Humphries 2000; Kent et al. 2002). REC's are multi-disciplinary bodies concerned with protecting the welfare, rights and dignity of all individuals involved in the research process (ESRC 2010) with some adopting a supporting and facilitative role (Hedgecoe 2008). However, many are perceived to present barriers to the research process (see for instance Tierney and Corwin 2009; Hammersely and Traianou 2011).

RECs comprise of academic staff but operate under pre-determined frameworks that are set by central university management and normally operate at a school or departmental level. A central committee often complements departmental bodies by setting policy and advising on tricky cases. So as Tierney and Corwin (2009) point out guidelines are developed by the university to protect its interests mindful of the modern litigious environment. These guidelines are interpreted by academics whose membership is part of their administrative obligations. Committees are highly formalised and procedural, representing a space where the clashing priorities of bureaucrats and academics crystallise. This causes problems such as basic wrangling over epistemological and methodological concerns; clashes over issues of consent, gatekeeping and access; and 
questioning on the certainty of the research field. Ethical review does not always offer clear direction for the researcher such as how to juggle conflicting interests or the dilemmas associated with undertaking covert observation (White, 2009; Richardson and McMullan, 2007). Equally harm is not necessarily offset by participants' stated willingness to participate. The seemingly over-zealous management approach to ethics can result in de-professionalisation and is argued to undermine reflexivity ${ }^{1}$, empowerment or facilitation in the research process (Cannella and Lincoln, 2007:318; Connolly and Reid, 2007; Tolich and Fitzgerald, 2006; White, 2009). Processes of ethical scrutiny clearly present problems as they fail to take account of the role of the academic community and of communities of practice in debating and making judgements on ethical issues (Boden et al. 2009; Tierney and Corwin 2009).

Ironically, the ethical review process can distract the researcher because 'ethical discussions in methodology have concentrated heavily on research relationships with respondents during data collection' (Doucet and Mauthner in Doucet and Mauthner 2002 p.140). This is perhaps a direct result of the legacy of medical ethics and so we see evidence of a 'moral panic' with disproportionate claims being made about the potential harm to research participants (van den Hoonaard 2002). It has been argued that the context of justification has taken precedence over the context of discovery (Doucet and Mauthner 2002): there appears to be a perception that the ethical review process favours research that is safe and entirely predictable. This is at the expense of more exploratory, cutting edge research on topics that may carry more risks, not so much to the researcher, or the researched, but to the academic institution. In other words, ethical review boards appear to be supporting 'safe' research so as to protect the reputation of the University and as such have become a tool of management. The analysis proceeds cognisant of the general acceptance that final responsibility for ethical practice lies with researchers (ESRC, 2005 and 2010; Richardson and McMullan, 2007). Hence the multiple contexts that influence the research process need to be dealt with by researchers. It is these broader relations that are analysed in the context of rural development research as a means of demonstrating how ethics can be a valuable asset that is driven by professional researchers.

\section{Ethics and rural development actors}

Influenced by wider neo-liberal agendas, significant economic restructuring and enhanced technology, rural areas have witnessed increased levels of mobility. Economic migration occurs as migrants avail of emergent employment opportunities in rural areas while being guaranteed a reasonable quality of life (Kandel and Cromartie 2004; Parra and Pfeffer 2006; CRC 2007; Jentsch and Simard 2009). Regions with little past experience of immigration have become destination areas for migrants including remote rural areas such as the Highlands of Scotland (de Lima et al. 2005), the mountainous areas of Northern Greece (Kasimis 2009); upstate New York (Parra and Pfeffer 2006); Alberta, Canada (Broadway 2007); and the US South (McConnell 2010) small towns and more accessible rural regions in Northern Ireland (Jarman 2005; Martynowicz and

\footnotetext{
${ }^{1}$ Although Crow et al. (2006) argue that in some cases the process can enhance reflexivity
} 
Jarman 2009). This offers both opportunities and challenges for rural communities as they attempt to accommodate the range of needs across and within different social groups.

Many of these 'static' areas are historically ethnically and racially homogenous (Pruitt 2009; McConnell 2010). Lacking the critical mass of their urban counterparts, and in a context of resource scarcity, they struggle to identify and subsequently meet the diverse needs of their 'new' rural communities (Animate 2005; de Lima et al. 2005; Pfeffer and Parra 2005; Jarman 2006; Pruitt 2009; McAreavey 2010a. 2010b,). Such communities may not have the knowledge and expertise to respond effectively to diverse social groups; lacking language skills, cultural competences and other integration mechanisms (Parra and Pfeffer 2006; McAreavey 2009; Martin and Phelan 2010). In these circumstances a breadth of interest groups including NGOs, churches, employers and friends become important support systems towards helping migrants access information and healthcare; availing of economic opportunities; and reducing isolation and inequalities (Jeanetta et al. 2009; Validivia and Dannerbeck 2009; Sandoval and Trabalzi 2010). As increasingly diverse communities are found within rural localities, the challenges of engagement through research and participation are heightened. This is particularly the case as formerly top-down agenda-setting and decision-making processes have been replaced by multilevel partnerships between the state and different interest groups within civil society (Warner 2001), as evidenced though the delivery and implementation of initiatives including the European Rural Development Programme (CEC 2005).

Identifying the different interest groups can raise challenges for the ethical researcher and practitioner wishing to exert what Brunn describes as an 'ethic of responsibility' (Bruun 2007 pp. 250-259 in Hammersley and Traianou 2011). This is further complicated as the notion of what is ethical can be different for different communities (Kent et al. 2002, Truman 2003, Graham et al. 2007, Hurdley 2010). Said's (1995) work on orientalism is instructive as it highlights how colonial power, conquest and control have shaped the study, research and conceptualisation of colonised persons as others, inferior and deficit. And so knowledge frameworks and their design and legitimacy have import for marginalised or vulnerable groups such as migrant communities and minority ethnic groups who have little control over the research process and so it becomes a site of struggle (Tuhiwai-Smith 1999). There is a need for research to take account of the involvement and the participation of minority participants so as not to reduce them to objects of research while also ensuring that their voices are heard (Kelman, 1972; Koch \& Harrington, 1998; Fisher \& Ragsdale, 2005). Some suggestions and strategies towards addressing these power issues include engaging with them in a manner that elicits their participation, is culturally sensitive and acknowledges their inputs (Moore, 1973; Fontes, 1998; Jensen \& Lauritsen, 2005; Sheikh, 2006).

\section{Empirical research}

The research informing this article explored the lived experiences of recent migrants to Northern Ireland. This 'require[d] talking to people, taking their perspectives, analysing their stories, and discovering the meaning of their actions through ethnography, participant observations, interviews, analyses of their diaries, letters and 
archives' (Chirkov 2009:97). The preliminary research was funded by an external body and was a qualitative study which set out to conduct eight interviews and two focus groups, one each with interpreters and NGOS from both areas. In fact the research comprised 18 interviews and four focus groups with migrants and key informants. It sought to examine migrants' micro-level experiences and expectations of life in Northern Ireland and to gain insight into conducting research with migrant communities. It was conducted in two rural areas, one in the border area with the Republic of Ireland and the other located approximately mid-way between this and Belfast. Research is ongoing in the locality and collaboration continues with key policymakers and other stakeholders.

Preliminary acquaintance was made with Susan, a volunteer from a Christian based voluntary body, Helpful provides advocacy support as well as household items to families and individuals to people 'in need' who are referred by members, statutory agencies or other voluntary organisations. It relies on volunteers, voluntary donations and fundraising to conduct its activities. As a gatekeeper, Susan provided initial access to migrants and from this a snowballing technique led to the identification of additional respondents. The majority of interviews and one of the focus groups were conducted on the premises of this charity. The remaining three focus groups were held with a Polish women's group in the other study area during their regular meetings. The payment of an honorarium to interviewees provided token recognition of their contribution. However, not everyone who was asked agreed to being interviewed and some who agreed chose not to respond to interview questions in any detail. Consent was granted from all participants in relation to their involvement in the research. All interviews and focus groups were recorded and transcribed with translation occurring as necessary. Pseudonyms were assigned to interviewees and organisations. The data was analysed and interpreted by reading and re-reading scripts, followed by a process of coding, so that emerging issues were identified and early ideas were elaborated or modified accordingly (Boeije 2010). Further methodological issues are explored in a forthcoming article.

\section{Northern Ireland: a diverse community}

The 'community' in Northern Ireland has changed substantially, no longer is it appropriate to consider it in binary terms (Ni Craith, 2002). Instead an increasingly diverse mix of groups represents the 'community' (NISRA 2010). On top of traditional ethno-religious community relations, issues of cohesion arise as a result of increased diversity arising from population mobility. Residential relocation, return migration and retirement migration flows are all important drivers of population redistribution in Northern Ireland, particularly to coastal, amenity rich areas which offer a higher quality of life for the pre-elderly / young old (Stockdale et al., 2011). European and international immigrants are also settling in Northern Ireland and it is these groups that are the focus for this research. 
The UK government requires nationals from the Accession State countries to the $\mathrm{EU}^{2}(\mathrm{~A} 8)$ to register under the Worker Registration Scheme (WRS) if they take up employment for more than one month's duration. These figures reveal that Northern Ireland attracted a proportionately larger number of A8 nationals than other areas of the UK (Beatty et al. 2006; NISRA 2009). Not confined to urban centres, predominantly rural areas such as those around Armagh, Craigavon and Ballymena have attracted immigrants. The Craigavon area now has the second largest ethnic population outside of Belfast (http://www.craigavon.gov.uk/images/stories/IntegratedDevelopment-Framework-2009-2011.pdf), while in Dungannon in 2007 6.8\% of the population was from A8 countries, as compared with 1.7 across Northern Ireland (NISRA 2007).

Although most people in Northern Ireland believe that migrant workers make their society open to new ideas and cultures (Gilligan 2008), it is also the case that Northern Ireland has in the past been dubbed the 'racehate capital' of Europe denoting the massive rise in racist attacks that emerged during and subsequent to the peace process in the late 1990s (Douglas in Lentin and McVeigh 2006). Ongoing distrust and tension is evident with the general public being less welcoming of the rights of EU citizens to live and work in Northern Ireland in 2008 than in the previous year ${ }^{3}$; meanwhile racial crime and incidences have persisted since 2005 (OFMDFM 2010).

\section{Multi-sectoral governance}

Social inclusivity has been central to Northern Ireland's legislation both following many years of an equality and fair employment agenda, and since the signing of the historic Northern Ireland Peace Agreement in 1998. The overarching government policy framework the 'Programme for Government' is premised on a number of core values including: sustainability, fairness, inclusion and equality of opportunity. By promoting tolerance, inclusion and wellbeing it aims to 'build a peaceful, fair and prosperous society' (http://www.northernireland.gov.uk/index/work-of-the-executive/programme-for-government-and-budgetv1.htm/). This has posed challenges for government in Northern Ireland as it strives to deliver policies and implement programmes that are fair, and perceived to be fair, across all members of its society while also dealing with issues of conflict.

Even though just under one third of the NI workforce is employed in the public sector compared with a UK average of 22 per cent, it is perceived to be remote from the people with little budgetary responsibility (Knox 2009). Public sector reform seeks to address these shortcomings by aligning administrative boundaries and by strengthening the role of local government so that public services can be delivered more effectively. Part of their enhanced function includes responsibility for rural development, urban and rural regeneration, local public realm aspects of roads, and community planning. Social, economic and environmental concerns are thus frequently advanced by a range of different bodies, including those advancing a rural development agenda.

\footnotetext{
2 Poland, Lithuania, Latvia, Estonia, Czech Republic, Hungary, Slovakia and Slovenia

${ }^{3} 67$ per cent of respondents to the Good Relations Indicator survey stated that they were very or fairly welcoming of the rights of EU citizens to live and work in NI, compared to 76 per cent in 2007.
} 
Underpinning European rural development policy (CEC 1988), this is reflected in the NI Rural Development Programme as it 'seeks to improve the quality of life in rural areas and to encourage diversification of economic activity' (NIRDP 2007). Meanwhile the proposed new Planning Bill (NI Assembly 2011) aims to address a democratic deficit, to enhance public decision making processes and to contribute to the quality of life of local communities. Integration, governance, leadership and stakeholder involvement have been cited as raising particular challenges for a range of stakeholders including professionals, officials, politicians and communities as they grapple with new functions and powers (McAreavey et al. 2011:5). Similar responsibilities for well-being arise within other sectors including health (Marmont 2010, Health and Social Care Board and Public Health Agency Northern Ireland 2011).

Evidently, numerous organisations have a remit to provide services within a particular locality. Rural development continues to operate through a territorial approach and so relies on 'joining up' with other sectors. The ethical researcher will aim to 'increase the sum of good in the world' (Israel \& Hay, 2006, p. 2). Within rural development research this entails careful navigation of partnerships that have sprung up under the guise of multi-sectoral governance and public sector reform. One of the perennial challenges for participatory governance is to ensure a joined up approach and to avoid duplication of effort.

\section{Implementing an 'ethics of responsibility'}

The REC at the time of my application was chaired by a civil engineer from my department. Comments on my applications for the migrant project made by the committee reveal what Goffman (1983) terms 'trained incompetence' (p.2 in Lemert and Branaman 1987). For example, the REC stated that there was a requirement for 'the inclusion of consent forms in English with assurances that other languages appropriate to the sample population will be created' (feedback from REC). Whilst such a request might seem reasonable and 'normal' the stipulation that a signed consent form be obtained would have proved a major hindrance in eliciting data from prospective respondents. In short, this requirement caused anxiety among research participants who were from a culture where form filling and officiousness were associated with a heavily policed state (Interview \#7, Stanislaw). Having considered this issue with colleagues and following a discussion with members from the central university committee, I was given permission to acquire verbal consent. This small example illustrates the way in which ethical review processes have been captured by managerialism and a belief that there is essentially only one ethical framework standard. It contrasts with the way in which ethics are situational and emerge through social relations in the field; they are not something to be judged from a distance as a one-off endeavour (Rossiter et al., 2000; Hemmings, 2006; Armbruster, 2008).

Getting started in the research field very quickly revealed how by its very nature, qualitative social science does not include a completely predetermined research design at an early stage (Truman, 2003; Connolly and Reid, 2007). More appropriate avenues for my research soon unfolded. The original conception for the pilot project was to develop a greater awareness of the lived experience of recent migrants to Northern Ireland as little was known beyond headline figures. I had planned to access respondents through two different channels: 
an NGO and a local food processing employer. The rationale behind this was that civil society characteristically provides a lot of support for migrants to new destinations (Pfeffer and Parra 2005) and many recent migrants to Northern Ireland were employed in the food processing industry. Having gained access to migrants via a local NGO, access through the employer was less forthcoming. Parallel to this, I had made connections with the local health trust and through a BME partnership they were keen to establish stronger links with the Polish community. This was at the specific request of the Polish Consulate Delegate following a spate of suicides within that community. In addition, anecdotal evidence suggested issues of relationship breakdown and alcohol abuse were emerging, although there was uncertainty over whether this was anything beyond incidences across society in NI more generally. These matters were exposed to me as a result of immersion in the research field and are reflective of the way in which the naturalistic environment is dynamic, complex and situational (Mauthner et al. 2002; Armbruster 2008).

It seemed that whatever direction I turned, ethical issues surfaced. I had indicated to key contacts that I wished to undertake research that added value to earlier studies and that would be of use in the development of policies and subsequent services. Following discussions with partners in the BME group, there was general agreement that my research could dovetail into their remit if I re-focused and undertook a series of focus groups with a Polish Women's Group (rather than two focus groups with NGOs and with interpreters as originally planned). Attention would be directed to general well-being along with the specific issue of health. Although I had not anticipated this direction for the research, I was not opposed to such a turn as I saw it as a potential opportunity to overcome barriers and to gain access to people from migrant communities. I weighed up the options and I discussed these issues with my 'community of practice' (Boden et al. 2009:733). Essentially I had not been successful in gaining access to respondents via an employer and time was moving closer to the completion date for my research. Moreover as a multi-agency and cross-sectoral partnership, the BME group with which I was working aimed to enhance the quality of life of local residents. Somehow with the issues of suicide and of emerging and as yet unknown social problems, it seemed that not pursuing this line of inquiry was not an option. Further and given that significant foundations of the research environment including its establishment, perspectives, structures, practices and outcomes are based on racialised and imperialistic frameworks (Young 1992, Tuhiwai Smith 1999), pursing this aspect of the research would provide a mechanism for these women to influence the research process.

There were ethical implications of not proceeding in this way: the research would not get done and service providers would not be able to refine their services to meet the needs of their increasingly diverse population. By choosing not to collaborate with key service providers in the area there was also a strong likelihood that I may have faced barriers to gaining access in the future. Meanwhile by having the endorsement of the different partners from the BME group the legitimacy of my research was enhanced: I was frequently asked if I was just a random researcher, or if I was doing the research with other agencies. When explaining the different organisations involved, I became quite adept at dropping the names of key individuals as a means of gaining access and ensuring positive responses. 
The all-pervading nature of research ethics relied on my constant care and attention as a professional researcher rather than automatic adherence to a concrete template as approved by the REC. It had approved a single focus group each with NGOs and with interpreters, rather than a series with Polish Women. But the research questions posed before entering the field were inappropriate once interactions with the phenomena under investigation commenced. The themes explored with the Polish Women were quite different to those originally outlined: explicit discussions on suicide, domestic violence and mental health were not anticipated. It would not have made any sense for the research to have been postponed pending a fresh application to the REC for undertaking the amended focus groups: in theory this would have been necessary as approval was granted following details of 'the broad schedule of the proposed questions or themes that will be addressed in both the interviews and focus groups' (Memo from Chair of REC to author, 22.06.07). As these processes can take some time there is a risk of research momentum being lost, jeopardising the rapport and positive relations established within the research field and ultimately placing the whole research project at risk. It is evident that the managerialist approach to ethics as an infallible and fixed device there is little accommodation for the 'spiral' of qualitative research (Gibson and Brown 2010: page). However under 'naturalistic' conditions mindful and reflective of the ethical implications of any new decision or changes in research tactics and drawing on an academic community of peers, a professional qualitative researcher simply adapts the research design to fit situations as they arise.

\section{Representing different voices within the research process}

Three focus groups were conducted with a Polish women's group over a period of three months, during the day and at their regular meeting time. A core group of women were present during all three focus groups, and at any one meeting approximately ten individuals attended. These groups were co-facilitated by the author and two interpreters, both of whom were also qualified psychologists. They were conducted in Polish, with simultaneous interpretation to English. On some matters I was in a position of power: I had access to some of the key agencies to whom I would feedback the research findings. On other matters I was less influential - I was reliant on meeting the women in their premises, at a time that suited them and communicating through an interpreter. I was wholly reliant on the ability of the interpreters to appropriately convey information and meaning. The act of interpreting is a political process and is notoriously riddled with challenges (Alexander et al. 2004; Temple 2008; Martin and Phelan 2010). Text and talk are rhetorical devices with interpreters not just reflecting identifies, but they produce them based on their own knowledge and experiences and drawing on the voices for whom then interpret. Some would argue that interpreters are not just mere instruments, but that they are key informants within the research process (Edwards 1998). The facilitation skills of the two interpreters were marked. As focus groups are less about a single voice or a consensus and more about how meaning is constructed (Barbour 2008), the nuances of discussion become a central feature of the data. One facilitator established a natural rapport with me and the women while the other was much less at ease throughout the process. This was evident in his hesitancy during the main sessions and afterwards at debriefings when he provided limited insight into the debate in comparison with his colleague who described 
in detail the intricacies of the various interactions. The gender difference of the facilitators influenced the rapport with the women in the group and with me as a researcher. In addition to gender, other issues including ethnicity affect researcher positionality and are likely to have impacted (Stanley and Wise 1993; Stanfield 1993). But more than this, the facilitator with whom I connected demonstrated cultural competence (Papadopoulos and Lees 2002) and served to do more than simply communicate a message.

The above scenario is illustrative of the messy nature of qualitative research and of the way in which ethical matters must be considered throughout the process. Judgments must be made regarding appropriate issues on which to trade-off. Clearly the circumstances were not entirely ideal for conducting research: being able to communicate directly with the researched in their own language would have been preferable to using interpreters. But the act of doing nothing is itself a political one as a 'side' has been taken (Armbruster 2008). I made the judgement that doing something to raise the profile of migrant communities was better than doing nothing. I was mindful of the fact that minority communities are often silenced within the research process or may be unable to challenge research that interprets their reality incorrectly (Knight et al. 2004; Jensen and Lauritsen 2005, Archer 2007, Koch and Harrington 1998; Maxey 1999) and of criticism that the community does not always receive feedback. Hence the production of knowledge and practice generated within social and political structures may be curtailed where minority communities have little control over the research process (Morelli \& Spencer 2000). By exercising my professional ethics I identified the need to set up a session with the Polish Women's group to present the findings from their series of focus groups and to seek to overcome potential for mis-representation through language difference. An informal presentation was simultaneously interpreted and handouts were provided with summary information translated into Polish. I used it to ensure that the information that they had communicated to me, via interpreters was in their opinion an accurate and fair reflection of our deliberations. Not only was this used to validate the data, but the women were encouraged to become an integral element of the research process. Subsequently the findings from the research were presented to a range of stakeholders, including the research participants, in a public forum. The legitimacy and valence of the activity was enhanced because of the involvement of the Polish nationals as partners and also because of connections between the researcher, the researched, policymakers and service providers. By doing this I recognised the importance of constant reflection and reinterpretation of ethical matters while in the research field.

\section{Hearing different voices within the research process:}

Even where ethics is considered as something inherent within the research process, priority tends to be given to research respondents to the neglect of other interest groups. Focusing so much attention on managing the welfare of participants can cause blind spots elsewhere. My research aimed to examine daily experiences of migrants. The following extended excerpt from the Polish Women's Focus Group encapsulates the key problems as perceived by these users and continues along the theme of ethical issues associated with language in the context of research with migrant communities:

F 1: What can you say about interpreting service? 
FG1: It's difficult. You can be sick, but the interpreter will be available in a week. You need to wait a week if you need an interpreter.

F1: $\quad$ So there are some difficulties?

FG2: Or you can use the telephone interpreting. But you are never sure if it is conveyed properly.

F1: $\quad$ You have to wait long for an interpreter

FG3: I have not had any personal experiences, but l've heard that interpreters often are...

FG 1: It is a problem.

FG3: They are not accurate. They say what they think they hear.

F1: $\quad$ Yes. They decide themselves.

FG3: And very often there are important issues...emotions, personal experiences, some tragic stories.

FG1: Yes, they change the meaning of information.

FG2: $\quad$ And they make a long story short.

FG3: Yes. They shorten the stories and you can tell from their expression that they take sides.

F2: I have recently completed an interpreter course, in September. And we were told that there are many interpreters who did this course 4.5 years ago. But the standards got higher in recent years, a lot higher. I was expected to write a couple of essays in English, it involved a lot of work. But I know that 4.5 years ago they were put on a register simply because they were able to speak Polish. [Facilitator one] you also mentioned that you did the course recently. Now they raised the standards, because...

FG3: It's a good sign. Because you need to be sure that when you talk about your emotions it is translated accurately. Exactly how you say it - not as the interpreter understands it. There isn't a problem when they translate what day of a week a person has an appointment. But it is different when people talk about more important issues. Then being partial is unacceptable.

F 2: $\quad$ But the interpreter must be impartial. That's the rule.

FG3: Impartial. There was this case in my family...My brother felt unfairly treated. The interpreter took side of a service provider and...

FG3: But the interpreter shouldn't take sides, but...

The quality and availability of interpretation services within the health centre emerged as a major barrier to accessing services, with questions arising in relation to cultural competency and the role of interpreters (see McAreavey 2010b for a fuller discussion). Following recommendations from the preliminary study, a professional development session was organized for interpreters across Northern Ireland to which I was invited to provide closing remarks. I had endeavored to maximize the impact of my research by developing 
extensive networks and this had evidently been successful. However, I was somewhat wrong-footed by the reaction of interpreters to my research. They revealed another side of the picture telling stories of emotionally difficult and overly long interpretation sessions; and of occasions where clients expected more from them than 'straightforward' interpretation. Despite my intentions to exercise professional ethics I had followed the direction of the REC and had focused almost entirely exclusively on the needs of research respondents. In so doing, I had overlooked the wider relationships that must be considered as part of responsible and ethical practice (Mauthner and Doucet). But this was somewhat rectified by paying attention to ongoing relations that facilitated my involvement during the professional development session. Engaging in a dialogic relationship (Denzin 1997) allowed for interchange between participants, recognizing the partiality of each input. Ethical issues associated with interpreting for very emotional and volatile situations were raised including the development of therapeutic relationships with interpreters rather than with health practitioners (01.06.11). Interpreters were caught between managing diverse expectations by meeting the needs of health professionals and those for whom they were interpreting. A range of different roles were described by translators: 'communicator'; 'advocate'; 'mediator'; 'cultural consultant'; 'counsellor' and 'neutral translator' (01.06.11) and also at different times by key service providers over the course of the research. This role confusion and resulting misaligned expectations represented serious professional hazards and often resulted in burnout among interpreters. The pressure on the interpreting service to meet the growing needs of a diverse community was marked: during the year ending March 2011, with 314 interpreters registered to provide services, it had received just short of 52,000 requests for interpretation across 36 languages. Figure one illustrates the increasing demand since its establishment in 2005.

\section{Insert figure 1 about here.}

Initially by focusing only on the respondents and not taking account of the wider research process I had inadvertently overlooked the voices of interpreters and I had failed to represent their interests. Their wellbeing was being compromised due to ethical dilemmas, role conflict, lack of cultural knowledge and inadequate support that they faced as interpreters. Simultaneously, there were no questions from the REC about the role and well-being of interpreters in the process. The fact that questions about the well-being of the translators emerged only during the course of the research serves to highlight the lack of 'ethical foreshadowing' by me and the REC. However, as I was immersed in the research milieu I was able to (partly) compensate for my oversight during the professional development session. Moreover, the experience has enhanced my awareness and sensitivity to look beyond the research respondents. Such is the nature of the ethical review process that I did not feel it was appropriate to feed this back to the committee: it did not occur to me that they would be interested in either the omission or in the consequential learning in a manner characteristic of a true community of learning. 


\section{Incentivising participants: Ethical Dilemma or Research Pragmatism}

I was reliant on the participation of migrants who were freely giving their time to the project and an honorarium was available to them in acknowledgement of this. This payment represented an incentive to participate rather than having to persuade or coerce them (Grant 2002). Ethical standards are upheld so long as this power relationship is not exploited and individuals make a free choice regarding their participation. This includes ensuring that risks are minimal and that they don't feel compelled to participate even though it might go against their better judgment; and so the incentive becomes indistinguishable from coercion (Grant and Sugarman 2004). The use of a payment could be seen as undermining important social values such as responsibility, participation and altruism with people being motivated to do 'the right thing' but for the wrong reasons (Valdivia and Dannerbeck 2009, Grant and Sugarman 2004). This has implications for future research activities especially if individuals expect even modest payments for their participation.

Questions arose in relation to one particular interviewee who had clearly been coerced by his wife to participate in the research. He responded in monosyllabic tones and showed little willingness to engage with the interview: his body language indicated uneasiness; he failed to give eye contact; and he exuded alcoholic fumes. Rather than terminate the interview prematurely, I took the decision to continue to a reasonable endpoint and to pay the honorarium. I was struck by this man's low level of self-esteem and the fact that he was reliant on his wife to negotiate and navigate much of his world beyond the home environment as he did not speak English nor did he attend language classes, and he worked with other Eastern European nationals. His wife had unquestionably traded on her power within their private life to influence his 'decision' to participate in the research. I did not consider that it was my position as a researcher to interfere with this personal arrangement; believing instead that intrusion would yield more serious ramifications for this man. This was essentially an evaluation of beneficence: the risk to the individual was minimised, while benefits were maximised.

Conscious of cultural differences and of how I had gained access to interviewees I endeavoured at all times to stress to participants that the payment would be made, whatever their input during the interview. As in any interview situation I also reminded them that they were free to leave at any time. I was unaware of the full extent to which interviewees believed they had a 'free choice' regarding their participation. In their home countries in Eastern Europe neglect towards authority figures had serious implications (Interviewees \# 1 Rasa; 7 Stanislaw; and 8 Mariya). They may have perceived a dependency relationship with Susan and so believed that they were obliged to participate in the research in exchange for the help offered to them.

\section{Conclusions}

Ethical and practical issues intertwine to influence the research process. In the real world it is sometimes the case that a less than perfect avenue must be selected. The point for the ethical researcher is that there is an awareness of the different choices and that there are positive outcomes that do not jeopardise or marginalise individuals. Part of the context for this research is that agencies are constrained to deliver the breadth and 
quality of services to adequately meet the new and expanding client base that is characteristic of contemporary rural areas. Thus of particular relevance for rural development now and increasingly in the future are the specific challenges associated with researching minority and migrant communities in order to understand and address their specific needs. In 'standard' social science research, representing the voices of the researched is a powerful responsibility (Griffin 1996). It was complicated in this research by language difference. Criticism could be made that it falls short of 'tidying up' the text (Esposito 2001) by engaging in a process of back translation into the original language and forward translation into the second language. Practical matters of timescale and limited funding meant that this was not an option. Instead the involvement of migrants within the design of the research sought to overcome these shortcomings while also addressing known limitations of knowledge production within these communities. Equally by demonstrating connections with social care groups I had the leverage to convince prospective participants that research findings would inform policy and practice and had the potential to shape services. Ensuring that the results were disseminated to the policy community was an output required by the funder. While arguments may be made that these influences and activities jeopardize researcher autonomy, they were not at odds with my professional judgement. In fact I firmly believed that these tasks were instrumental in establishing connections; developing rapport and getting on with the research.

There were ethical questions around ensuring public funds are used effectively - by partnering with other agencies, duplication was avoided and leverage was achieved. The consideration of ethics as a narrow, onedimensional management exercise as dealt with at the institutional level does not support or encourage this reflection. It ignores the context-laden nature of ethics and fails to appreciate the 'varied degrees' of ethical responsibility (Doucet and Mauthner 2008 p. 141). It is not clear how, if at all, the REC model would have dealt with the shortcomings that transpired in the course of my research. Certainly there appears to be little mechanism within a managerial approach to ethics for considering the wider epistemological issues of how knowledge is created, justified and validated. That is where the ethical practitioner must exercise integrity and set an agenda for responsible and professional ethics. Increasing levels of diversity within rural areas means that corresponding research must pay attention to knowledge claims and the relationships with the different communities who are affected by, and interested in, the research. As a researcher embedded in a professional community of practice I was able to reflect on and address the shortcomings to my research, such as the absence of the interpreters' voices.

In this study by weighing up the ethics of not collaborating with local agencies and conscious of the objective of increasing the overall benefits from the research, I framed the emerging relationships within a wider context. This went beyond the respondents to include those communities and individuals who will read, use and build on the knowledge generated - i.e. those involved in the production of knowledge, theory and policy. This helped to establish the legitimacy of the research and it contributed to the development of rapport with the researched. Nonetheless questions - ethical and methodological - remain around the extent to which it is possible to represent experiences of migrants through filters of access, representation and interpretation. 
These are matters that merit further consideration by rural development researchers given a context of increased and increasing diversity. But there are unlikely to be explored within the 'rarefied space' (Truman, 2003, para 42) of the ethics committee which is far removed from that of research practice where real people with personal stories, particular circumstances and different morals exist.

Institutional or bureaucratic ethics are thus quite different to professional ethics. This research reveals how ethical issues emerge on a daily basis for the researcher; they pervade the research process and require instant responses to often unexpected and unanticipated situations. It would be unfeasible for a researcher to go back to the authorising REC to ascertain permission for unexpected changes in the research direction, as necessary under a managerial approach to ethics. Instead the consequences of pursuing particular courses of action in the real world must be evaluated, often instantaneously, by the researcher. The very fact that I had brought an overarching ethical approach to the research meant that I was in a position to respond to events as they unfolded such as the failure to attend to the needs of interpreters or the opportunities to go 'off-piste' and reconsider the original research questions to pursue issues of health and well-being. In this way qualitative research does not follow a pre-determined template with ethical issues dealt with from the outset. This can be challenging and confusing for some REC members, especially for those from a natural or physical science background as they conduct experimental research premised on very predetermined frameworks.

Some have urged academics to reclaim ethics as a broader process associated with rigorous research recognising that is it not a driver to the research (Hammersely and Traianou 2011). After all knowledge production, they argue is the ultimate objective. This is not being disputed. However, attention to ethics helps to inform and direct the general logic of inquiry, the way in which knowledge is produced and the significance of the research overall. It supports the creation of connected relationships that recognises and scrutinises the partiality of different research participants and that respects the context specific nature of rural development research. Research ethics is not a zero sum game where attention from bureaucrats displaces the ability of researchers to consider ethical matters. Instead it would be more constructive to accept a management role in the governance of research through ethical review. However, it is imperative this does not purport to provide anything more than a snapshot review of an anticipated course of action that is recorded for the purposes of management. Researchers need to remain alert so that they do not become instruments of control through such management arrangements. By continuing to engage with communities of knowledge, research ethics becomes an asset to the professional researcher facilitating reflexivity and contributing to research that is socially engaged, cutting-edge and relevant. 